\title{
Sex and genetic variation in a helicid snail
}

\author{
L. M. COOK \& L. A. LACE \\ Department of Environmental Biology, University of Manchester, Manchester M13 9PL, U.K.
}

\begin{abstract}
Variation at enzyme loci has been investigated in the endemic Madeiran land snail Heterostoma paupercula (Gastropoda: Helicidae). There is a high degree of differentiation between populations. Part of the variation (about half of the total as measured by $F$ statistics based on three polymorphic loci) is the result of divergence between populations of different islands. There are morphological differences between populations in shell form and the structure of the aperture, and of the genitalia, which have been used to define separate taxa, but these do not show a clear geographical pattern. In the present results, the variation in the genitalia appears to be a polymorphism restricted to a few populations, in which some individuals are euphallic cross-fertilizing hermaphrodites, while others are hemiphallic individuals exhibiting partial selfing. It is suggested that these may in fact be part selfing, part female. This is a breeding pattern which could result in polymorphism.
\end{abstract}

Keywords: breeding system, genetic diversity, Heterostoma, land snail, Madeira.

\section{Introduction}

Lowe (1831) described one of the helicid land snails of Madeira as Heterostoma paupercula. It is very small for a helicid, being about $4-6 \mathrm{~mm}$ in diameter and flattened with a rather irregular shell and downturned mouth. Large numbers are sometimes found together tightly adhering under volcanic rocks in dry, sparsely vegetated parts of the islands. The geographical range of Lowe's taxon is eastern Madeira, the Deserta islands and Porto Santo and its adjoining islets (Fig. 1). Colonies also occur in the Azores and the Canaries (Backhuys, 1975; Wollaston, 1878). Individuals vary in size and degree of smoothness of the shell, in presence or absence of teeth in the shell mouth and in whether the epiphallic genital structures are fully formed. Mandahl-Barth (1943) examined these features, and divided his material into two species. His $H$. paupercula contained animals with a well-deflected lip, a distinct discontinuity in growth of the final whorl, a tooth in the shell mouth and lacking the flagellum and epiphallus from the genitalia. The other species with smooth growth to the shell, no tooth and euphallic genitalia he named Steenbergia duplex, using a different generic name because of the extent of the genital differences. One subspecies, $S$. $d$. desertae, was the only taxon living on the Deserta islands, while the supposed distribution on Madeira and Porto Santo is unclear from his paper. Backhuys (1975) found that animals from the Azores had the apical tooth but did not have reduced genitalia, and it became apparent that the characters used to make the distinctions were not exclusive. Waldén (1983) found that individuals like $S$. $d$. desertae lived on Madeira along with those with shells like Heterostoma paupercula, so he designated this group a new species Steenbergia desertae.

The presence of sufficient variation for two generic names to have been employed for animals which are nevertheless distinct from all other taxa in the Madeiran fauna makes it interesting to examine possible evolutionary patterns. Populations from all parts of the range in the Madeiras have been studied with a view to mapping and assessing the variation (Lace, 1990, 1992). The characters do not assort in such a way as to suggest that there are recognizable sympatric species. The animals from the Desertas are small and lack the apical tooth. On Madeira, size varies and declines from west to east along the eastern peninsula. Most populations lack the apical tooth, but it is present in others, and sometimes samples have both types present. The animals are large on the Porto Santan Islands. The tooth is usually present in samples from Porto Santo, but populations are variable in this respect on three other islets, the Ilhéu de Ferro, the Ilhéu de Baixo and Ilhéu de Cima. Of 361 individuals from 50 samples covering the full geographical range, hemiphallic individuals were found at only two localities, one on the Ilhéu de Cima and one on the mainland of Porto Santo nearby (Lace, 1990). In both cases, the samples contained both euphallic, toothed individuals and hemiphallic individuals lacking a tooth. Thus, the evidence from morphology indicates that there is some 


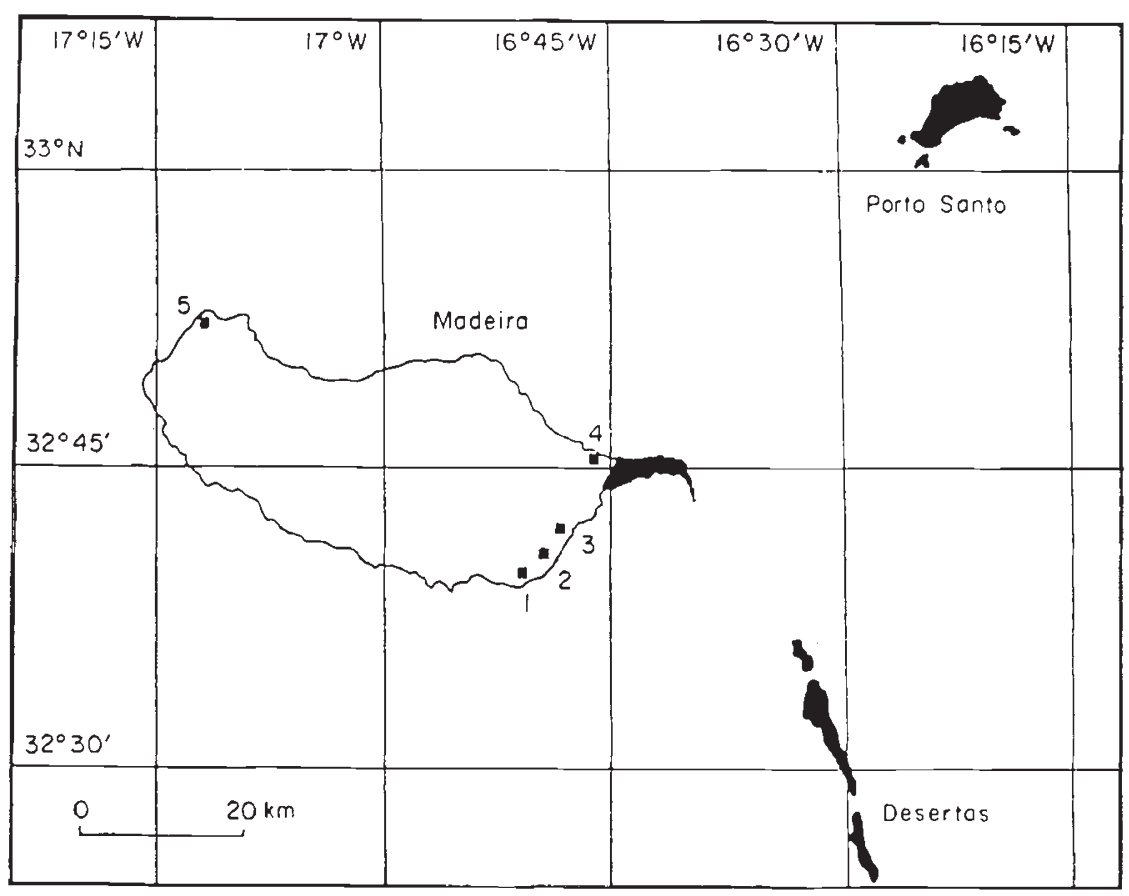

Fig. 1 Distribution of Heterostoma on the Madeiran islands. The main areas of occupation are shown in black. Occasional occurrences are recorded at the numbered sites on Madeira, of which site 4 is Boca do Risco. Lying offshore from Porto Santo are, from left to right, the islets of Ferro, Baixo and Cima. From Lace (1992). variation attributable to geography (animals from the Desertas are small, those from Porto Santo are usually large, etc.) and the original taxonomic distinctions do not stand up, taxonomic characters appearing in different associations in different places. Genetic variation between populations was also examined. In this paper we present the genetical results and consider the possible significance of hemiphally.

\section{Materials and methods}

Populations were sampled by searching under rocks in areas which were roughly $5 \mathrm{~m} \times 5 \mathrm{~m}$. Animals were stored in cardboard boxes and returned live to the laboratory. Some of these were then frozen while others were examined fresh. Samples from 34 sites were examined for enzyme variation by starch gel electrophoresis. The locations of the populations from which they come fall into five groups, the Madeiran peninsula (MD), the two islets at the east of the peninsula (MI), the Deserta islands (DS; all those studied here coming from Deserta Grande), Porto Santo (PS) and islets off Porto Santo (PI).

Enzymes examined were leucine aminopeptidase (LAP), glucose phosphate isomerase (GPI), glutamate oxaloacetate transaminase (GOT), esterase (EST), phosphoglucomutase (PGM), purine nucleoside phosphorylase (PNP), and peptidase (PEP). Scorable results were obtained for 1190 individuals, no differences being observed between fresh and frozen material. All seven enzyme systems were polymorphic, but results varied in ease of interpretation. The first three (LAP, GPI and GOT) were represented by single loci and alleles could be scored to provide allele and genotype frequencies. The others presented more difficulty because we have been unable to breed the animals. PGM produced consistently clear bands, but they proved difficult to interpret owing to the presence of sub-bands and probably of several loci. EST undoubtedly consisted of several loci; intensity of staining was variable for PNP. Band mobilities were therefore scored for these and PEP, but were not resolved into allele or genotype frequencies. The results are shown in Tables 1 and 2, which provide frequencies for LAP, GPI and GOT and a summary of the samples for the other four systems. Details are given in Lace (1990).

\section{Results}

For the three loci where heterozygote frequencies were scored, most samples showed a deficiency compared with Hardy-Weinberg expectations (Fig. 2). This could be a result of inbreeding or, in view of the small size, low mobility and local high densities of the animals, it could indicate differences in allele frequency between different parts of the sampling areas. Using the data in Table 1 to calculate Wright's inbreeding coefficients (as described, for example, by Hartl \& Clark, 1989), we find $F_{\text {IS }}=0.245$. The curve in Fig. 2 represents the 
Table 1 Data on enzyme variation in Heterostoma paupercula. Allele frequencies for LAP, GPI and GOT. MD = Madeiran mainland; MI = islands at end of the Madeiran peninsula; DS $=$ Deserta Grande; $P S=$ Porto Santo; $P I=$ islands off the Table 2 Summary of data on isozyme variability for systems not scored for allele GPI, allele 1 is present in one sample not shown here because data for the other loci are not available. PS6 and PI1 are samples from populations polymorphic for euphallic $(\mathrm{E})$ and hemiphallic $(\mathrm{H})$ individuals. Data for euphallics only are used in estimates of $F$ and cluster analysis

\begin{tabular}{|c|c|c|c|c|c|c|c|c|}
\hline \multirow[b]{2}{*}{ Sample } & \multirow{2}{*}{$\begin{array}{l}\text { Sample } \\
\text { size }\end{array}$} & \multicolumn{5}{|c|}{ Alleles } & & \\
\hline & & 1 & 2 & 3 & 4 & 5 & & \\
\hline \multicolumn{9}{|c|}{ Leucine aminopeptidase } \\
\hline MD1 & 27 & 0.20 & 0.80 & 0 & 0 & 0 & & \\
\hline MD2 & 35 & 0 & 0 & 0.41 & 0.59 & 0 & & \\
\hline MD3 & 16 & 0 & 0 & 1.00 & 0 & 0 & & \\
\hline MD4 & 51 & 0 & 0 & 0.78 & 0.22 & 0 & & \\
\hline MD6 & 39 & 0 & 0 & 0.51 & 0.49 & 0 & & \\
\hline MD6 & 26 & 0 & 0 & 0.77 & 0.23 & 0 & & \\
\hline MI1 & 64 & 0 & 0 & 0.80 & 0.20 & 0 & & \\
\hline MI2 & 24 & 0 & 0 & 0.60 & 0.40 & 0 & & \\
\hline MI3 & 44 & 0 & 0 & 0.51 & 0.49 & 0 & & \\
\hline MI4 & 43 & 0 & 0.14 & 0.74 & 0.12 & 0 & & \\
\hline DS1 & 24 & 0 & 0 & 0 & 0.67 & 0.33 & & \\
\hline DS2 & 26 & 0 & 0 & 0.54 & 0.44 & 0.02 & & \\
\hline DS3 & 20 & 0 & 0.10 & 0.43 & 0.45 & 0.02 & & \\
\hline PS1 & 26 & 0 & 0 & 1.00 & 0 & 0 & & \\
\hline PS2 & 23 & 0 & 0.35 & 0.63 & 0.02 & 0 & & \\
\hline PS3 & 34 & 0 & 0.07 & 0.60 & 0.32 & 0 & & \\
\hline PS4 & 31 & 0 & 0 & 1.00 & 0 & 0 & & \\
\hline PS5 & 29 & 0 & 0.10 & 0.90 & 0 & 0 & & \\
\hline PS6 & 8 & 0.13 & 0.87 & 0 & 0 & 0 & & \\
\hline PS7(E) & 14 & 0 & 0.89 & 0.07 & 0.04 & 0 & & \\
\hline $\operatorname{PS} 7(\mathrm{H})$ & 20 & 0 & 1.00 & 0 & 0 & 0 & & \\
\hline PI1(E) & 70 & 0.04 & 0.86 & 0.04 & 0.06 & 0 & & \\
\hline PI1(H) & 65 & 0 & 1.00 & 0 & 0 & 0 & & \\
\hline PI2 & 41 & 0.06 & 0.85 & 0.06 & 0.03 & 0 & & \\
\hline PI3 & 35 & 0 & 0 & 0.93 & 0.07 & 0 & & \\
\hline \multirow[t]{2}{*}{ PI4 } & 35 & 0 & 0.07 & 0.77 & 0.16 & 0 & & \\
\hline & & \multicolumn{7}{|c|}{ Alleles } \\
\hline Sample & $\begin{array}{l}\text { sime } \\
\text { size }\end{array}$ & 2 & 3 & 4 & 5 & 6 & 7 & 8 \\
\hline \multicolumn{9}{|c|}{ Glucose phosphate isomerase } \\
\hline MD1 & 26 & 0 & 0.10 & 0.10 & 0.12 & 0.37 & 0.32 & 0 \\
\hline MD2 & 37 & 0.41 & 0.04 & 0 & 0.37 & 0.17 & 0.01 & 0 \\
\hline MD3 & 23 & 0.09 & 0 & 0 & 0.17 & 0.74 & 0 & 0 \\
\hline MD4 & 50 & 0 & 0 & 0 & 0 & 1.00 & 0 & 0 \\
\hline MD5 & 47 & 0 & 0 & 0 & 0 & 1.00 & 0 & 0 \\
\hline MD6 & 25 & 0.56 & 0.04 & 0 & 0.02 & 0.38 & 0 & 0 \\
\hline MI1 & 67 & 0 & 0 & 0 & 0 & 0.90 & 0 & 0.10 \\
\hline MI2 & 26 & 0 & 0.02 & 0 & 0 & 0.98 & 0 & 0 \\
\hline MI3 & 48 & 0.08 & 0.01 & 0 & 0.02 & 0.89 & 0 & 0 \\
\hline MI4 & 43 & 0 & 0.05 & 0 & 0.10 & 0.85 & 0 & 0 \\
\hline
\end{tabular}


Table 1 Continued

\begin{tabular}{|c|c|c|c|c|c|c|c|c|}
\hline \multirow[b]{2}{*}{ Sample } & \multirow{2}{*}{$\begin{array}{l}\text { Sample } \\
\text { size }\end{array}$} & \multicolumn{7}{|c|}{ Alleles } \\
\hline & & 2 & 3 & 4 & 5 & 6 & 7 & 8 \\
\hline DS1 & 29 & 0 & 0.83 & 0 & 0 & 0.16 & 0 & 0.02 \\
\hline DS2 & 25 & 0 & 0.70 & 0 & 0 & 0.30 & 0 & 0 \\
\hline DS3 & 8 & 0 & 0.80 & 0 & 0 & 0.20 & 0 & 0 \\
\hline PS1 & 24 & 0.10 & 0.35 & 0.08 & 0.27 & 0.13 & 0.06 & 0 \\
\hline PS2 & 26 & 0.19 & 0.37 & 0.04 & 0.09 & 0.25 & 0.06 & 0 \\
\hline PS3 & 35 & 0.37 & 0.20 & 0.20 & 0.03 & 0.16 & 0.04 & 0 \\
\hline PS4 & 32 & 0.28 & 0.50 & 0.13 & 0.07 & 0 & 0.02 & 0 \\
\hline PS5 & 32 & 0.67 & 0.33 & 0 & 0 & 0 & 0 & 0 \\
\hline PS6 & 16 & 0.63 & 0.22 & 0.13 & 0.03 & 0 & 0 & 0 \\
\hline PS7(H) & 15 & 0.23 & 0.77 & 0 & 0 & 0 & 0 & 0 \\
\hline $\mathrm{PI} 1(\mathrm{E})$ & 53 & 0.06 & 0.49 & 0.03 & 0.09 & 0.26 & 0.05 & 0.01 \\
\hline $\mathrm{PI} 1(\mathrm{H})$ & 51 & 0 & 0.15 & 0 & 0 & 0.85 & 0 & 0 \\
\hline PI2 & 41 & 0.02 & 0.63 & 0.01 & 0.10 & 0.22 & 0.01 & 0 \\
\hline PI3 & 35 & 0.16 & 0.47 & 0.03 & 0.19 & 0.14 & 0.01 & 0 \\
\hline PI4 & 36 & 0.06 & 0.56 & 0.03 & 0.10 & 0.17 & 0.07 & 0.03 \\
\hline \multirow[b]{2}{*}{ Sample } & \multirow{2}{*}{$\begin{array}{l}\text { Sample } \\
\text { size }\end{array}$} & \multicolumn{5}{|c|}{ Alleles } & & \\
\hline & & 1 & 2 & 3 & 4 & 5 & & \\
\hline \multicolumn{9}{|c|}{ Glutaminate oxaloacetate transaminase } \\
\hline MD1 & 7 & 0.07 & 0.93 & 0 & & & & \\
\hline MD2 & 35 & 0 & 0.34 & 0.66 & & & & \\
\hline MD3 & 23 & 0 & 0 & 1.00 & & & & \\
\hline MD4 & 53 & 0 & 0 & 1.00 & & & & \\
\hline MD5 & 46 & 0 & 0.02 & 0.98 & & & & \\
\hline MD6 & 24 & 0 & 0.50 & 0.50 & & & & \\
\hline MI1 & 67 & 0 & 0.04 & 0.96 & & & & \\
\hline $\mathrm{MI} 2$ & 17 & 0 & 0 & 1.00 & & & & \\
\hline MI3 & 47 & 0 & 0.23 & 0.76 & & & & \\
\hline MI4 & 46 & 0 & 0.06 & 0.94 & & & & \\
\hline DS1 & 30 & 0 & 0 & 1.00 & & & & \\
\hline DS2 & 26 & 0 & 0 & 1.00 & & & & \\
\hline DS3 & 8 & 0 & 0 & 1.00 & & & & \\
\hline PS1 & 25 & 0.08 & 0.82 & 0.10 & & & & \\
\hline PS2 & 29 & 0.05 & 0.79 & 0.16 & & & & \\
\hline PS3 & 27 & 0 & 1.00 & 0 & & & & \\
\hline PS4 & 29 & 0.02 & 0.78 & 0.20 & & & & \\
\hline PS5 & 28 & 0 & 0.75 & 0.25 & & & & \\
\hline PS6 & 11 & 0.09 & 0.91 & 0 & & & & \\
\hline PS7(E) & 10 & 0 & 0.70 & 0.30 & & & & \\
\hline PS7(H) & 12 & 0 & 1.00 & 0 & & & & \\
\hline $\operatorname{PI1}(\mathrm{E})$ & 70 & 0 & 0.96 & 0.04 & & & & \\
\hline $\mathrm{PI} 1(\mathrm{H})$ & 61 & 0.06 & 0.94 & 0 & & & & \\
\hline $\mathrm{PI} 2$ & 30 & 0.03 & 0.93 & 0.04 & & & & \\
\hline PI3 & 35 & 0 & 0.94 & 0.06 & & & & \\
\hline PI4 & 34 & 0.02 & 0.88 & 0.10 & & & & \\
\hline
\end{tabular}


Table 2 Summary of data on isozyme variability for systems not scored for allele frequency

\begin{tabular}{lllll}
\hline $\begin{array}{l}\text { Enzyme } \\
\text { system }\end{array}$ & $\begin{array}{l}\text { Number of } \\
\text { samples }\end{array}$ & $\begin{array}{l}\text { Mean sample } \\
\text { size }\end{array}$ & $\begin{array}{l}\text { Number of } \\
\text { bands scored }\end{array}$ & $\begin{array}{l}\text { Maximum number } \\
\text { per sample }\end{array}$ \\
\hline EST & 26 & 30.1 & 17 & 16 \\
PGM & 34 & 35.0 & 6 & 6 \\
PNP & 30 & 33.1 & 13 & 7 \\
PEP & 27 & 30.7 & 17 & 14 \\
\hline
\end{tabular}

For enzyme details see text.

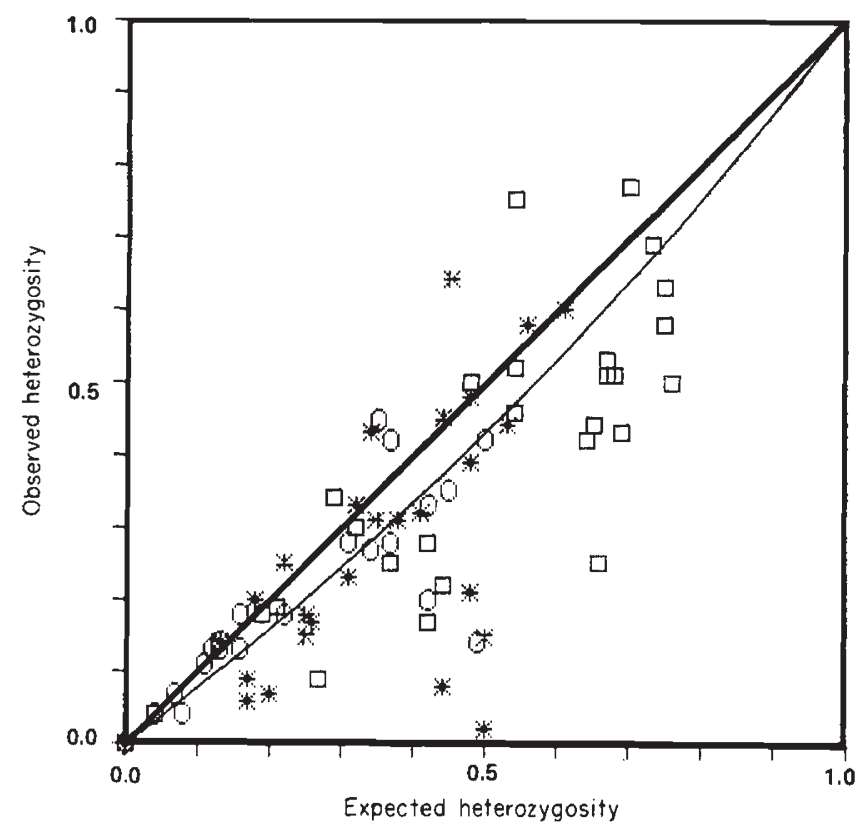

Fig. 2 Relation of observed to expected heterozygosity for three enzyme loci. $\left(^{*}\right)$ LAP, ( $\square$ ) GPI, (O) GOT. The curved line shows the pooled heterozygote deficiency for all samples.

average reduction in heterozygosity, indicated by this value. Overall, the total coefficient $F_{\text {IT }}$ is 0.574 and the between-population value $F_{\mathrm{ST}}$ is 0.435 . These values indicate a high degree of differentiation between populations, and as stated above, one reason is likely to be the low mobility of these small and secretive snails. The total sampling was spread across the three island groups of Madeira, the Desertas and Porto Santo. A between-group $F$ value may be calculated, as the between-population value may be resolved into a between-population, within-island and a betweenisland component. If $G$ represents the island grouping, $1-F_{\mathrm{ST}}=\left(1-F_{\mathrm{SG}}\right)\left(1-F_{\mathrm{GT}}\right)$. The calculated values are $F_{\mathrm{SG}}=0.230$ and $F_{\mathrm{GT}}=0.267$. The overall differentiation between populations therefore has a geographical component, relating to the island group.
Geographical differentiation may also be seen using clustering methods. Average values for Nei's $I$ were clustered for the three loci scored for allele frequencies, and clustered using the UPGMA method on sPSS (Fig. 3). This procedure establishes four groups. Most of the Madeira samples cluster together in one group and the samples from the Desertas in another. Samples from Porto Santo fall into two groups, which also include some of those from Madeira. At least one of these (MD1) is an odd sample from the Boca do Risco at the western end of the sampling on Madeira, which has other affinities with Porto Santo (Lace, 1992). At least to some extent, however, the grouping is geographical. When the same procedure was used for the bands scored for the other four enzyme systems, three groups were produced, the Porto Santo samples falling into two of them, with MD1, the rest of Madeira and the Desertas falling in the third. Clustering is only concerned with the similarities and differences in banding patterns between samples, so that in principle both sets of data should give the same result. However, if mobilities of alleles at different loci in the same enzyme system overlap this would reduce the differentiation, as has occurred with the Madeira and Deserta samples.

Genetic results are therefore consistent with morphological results. Overall, there is a mixture of characters which does not show clear evidence of the presence of sympatric species on any of the islands, and the safest conclusion is that these do not exist.

Two samples (PS7 and PI1) consist of a mixture of small, euphallic individuals with apical teeth and larger hemiphallic untoothed animals. Only the euphallic part is included in the above analyses. The data for the hemiphallics are shown, with the rest, in Table 1. There is less variability than is exhibited by euphallics in the same sample, LAP is monomorphic in both cases and GOT in one. The hemiphallic individuals are, however, polymorphic for some alleles. The alleles they have are ones present in the other individuals from their respective colonies. Where an allele is rare in the euphallic part of the sample it is rare or absent in the hemiphallic part. The biggest difference between euphallics and 


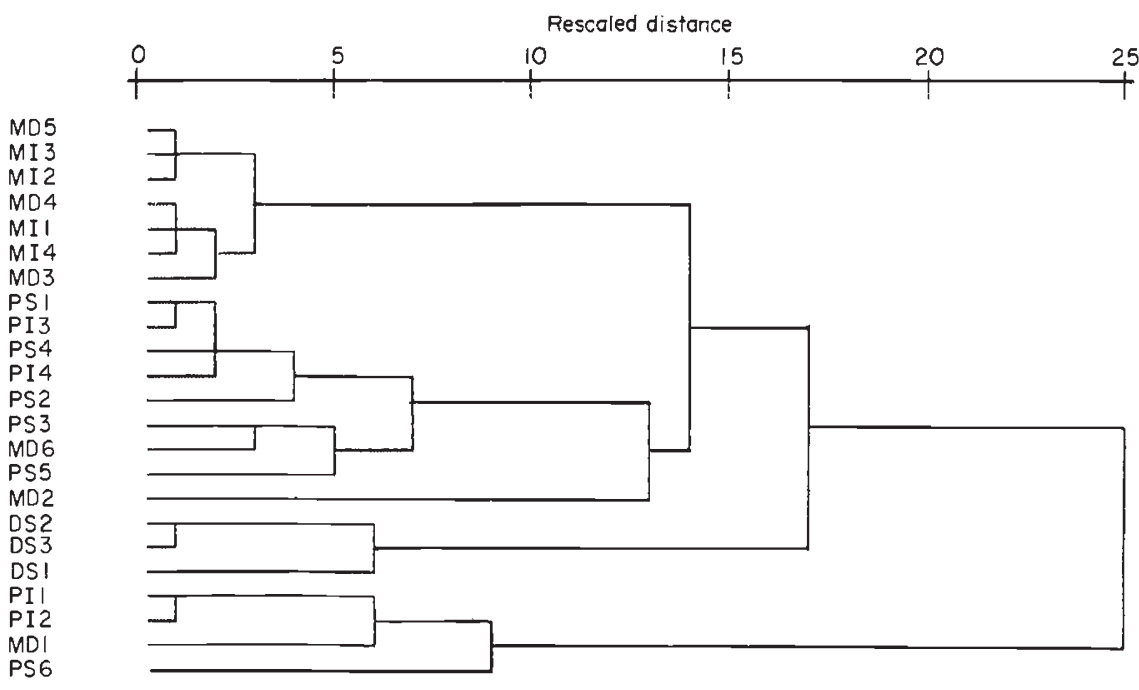

Fig. 3 Similarity of sample using Nei's identity and UPGMA clustering on SPSS. $\mathrm{MD}=$ Madeira MI = Madeiran islands; DS $=$ Deserta Grande; $P S=$ Porto Santo; PI = Porto Santan islands. hemiphallics from the same location occurs with GPI in colony PI1, where allele 6 is more common among hemiphallics than euphallics and allele 3 less common. We cannot explain this discrepancy, but a possible reason why there should be lower heterozygosity and absence of rarer alleles in hemiphallics is that they are partially self-fertilizing. Of course, we have not ruled out partial self-fertilization in animals from all the other, euphallic, populations. However, the morphological data do not suggest that colonies are composed of mixtures of separate morphotypes, and the family is one in which the species are usually obligate crossfertilizers. It is therefore most economical to suggest that these are too, and that the high inbreeding level is the result of low mobility and elevated levels of mating between close relatives.

Considering the average for the hemiphallics from both populations, the observed heterozygosity $H_{\mathrm{o}}$ is 0.118 and the expected value $H_{\mathrm{e}}$ is 0.184 . The level of selfing may be estimated (Hartl \& Clark, 1989) as $S=$ $2\left(H_{\mathrm{e}}-H_{\mathrm{o}}\right) /\left(2 H_{\mathrm{e}}-H_{\mathrm{o}}\right)$. This provides $S=0.528$, but inbreeding is evident in the euphallic populations, which we assume to be cross-fertilizing, measured by $F_{\text {Is }}=0.245$. If the expected heterozygosity is reduced proportionally the estimate becomes 0.262 . The estimated selfing level is therefore between $\frac{1}{4}$ and $\frac{1}{2}$.

\section{Discussion}

The results show that there is a high degree of variation between populations. This is consistent with the low mobility and the considerable time-scale over which the animals have been present on the islands. Wollaston (1878) pointed out that Heterostoma paupercula could easily be dispersed by human agency, and one population from Madeira (MD1) which has affinities with those from Porto Santo, could be an example (Lace, 1992). Nevertheless, this endemic species is present in fossil deposits on both Madeira and Porto Santo, specimens from Madeira dating back some 6000 years (Cook et al., 1992). Neither the morphological nor the genetic data are distributed so as to suggest that different species co-exist on the same island.

If the variation in structure of the genitalia does not stand up as a good taxonomic discriminator, it is interesting to consider what functional significance it may have. All pulmonates have a hermaphrodite breeding pattern. Many are obligate outcrossers, although some are self-fertilizing (Selander \& Kaufman, 1973). The usual pattern is for there to be a reciprocal exchange of sperm, which are stored and used in fertilization after the eggs have developed. Sperm transfer takes place in a spermatophore, which is made in the flagellum and epiphallus. In some pulmonate groups which lack a flagellum such as the Zonitidae, spermatophores develop in the vas deferens (Germain, 1930). Rumina decollata (Subulinidae), which selfs, lacks a flagellum, but so does Theba pisana (Helicidae), which is cross-fertilizing. The hemiphallic conditions therefore does not certainly indicate a deficiency, but it is very likely that within a species individuals without these structures are less good at sperm transfer than those which have them. Similar arguments have been applied to other pulmonate groups in which there is variation in development of the male apparatus (Watson, 1934; Riedel, 1953; Tompa, 1984).

The hemiphallic individuals obtained in this survey were found in association with euphallic animals. They have alleles in common with the euphallics and are polymorphic, although more homozygous. It is therefore possible that the two groups interbreed but that 
there is a degree of selfing. As hemiphallics have been found before in other combinations with the variable morphological characters, they are probably more widespread than this study shows.

If individuals are either entirely selfing or entirely outbreeding, selfing should replace outbreeding, if selfers are at an advantage, or be lost if selfing is disadvantageous. If selfing is an option during hard times, then both patterns may operate together in the same individual (Damgaard et al., 1992). Various combinations are known to occur in molluscs. Arionid slugs, for example, are often either selfing or outcrossing species, although some combine both strategies (Williamson, 1959; Foltz et al., 1982). Among snails, Liguus fasciatus (Bulimulidae) is a partially selfing species (Hillis, 1989; Hillis et al., 1991). In Heterostoma, the evidence suggests partial selfing in the hemiphallics and exchange of genes with the euphallics, probably as a result of receiving sperm rather than donating them. It is interesting to note that such a system, in which some individuals are part female, part selfing, could result in a polymorphism. We can obtain a general picture of the conditions required by adapting the notation of Charnov et al. (1976; see also Maynard Smith, 1978). The details depend on the inheritance of the characters involved.

In the model of Charnov et al. (1976), a male produces $N$ gametes, a female $n$ gametes and a hermaphrodite $\alpha N$ plus $\beta n$ gametes. There are $m, f$ and $h-$ males, females and hermaphrodites, respectively. Altogether the population produces $R$ offspring, the contributions from the three types being $R /(m+\alpha h)$ from a male, $R /(f+\beta h)$ from a female and $R[\alpha /$ $(m+\alpha h)+\beta /(f+\beta h)]$ from a hermaphrodite. These are the fitnesses of the three types, using fitness to mean the expected number of offspring produced by an individual. The first step in establishing what equilibria exist is then to find the conditions under which fitnesses are equal. In doing so, we are dealing which ratios or frequencies, so that $R$ can be dropped and the $m, f$ and $h$ values may be taken to be frequencies. This model is adapted below to consider the possible significance of the hemiphallics.

Suppose that a population consists of a frequency $h_{1}$ of cross-fertilizing hermaphrodites (the euphallics in the present case), and $h_{2}$ of hemiphallics, which are partly selfers and partly outbreeders with unequal contribution of male and female gametes to the next generation. Let $\alpha$ be the contribution of sperm by hemiphallics, relative to 1 for euphallics, and $\beta$ be the contribution of eggs, as in the model of Charnov et al. An individual reproducing by self-fertilization is assumed to use $\gamma$ sperm, relative to 1 for euphallics, and $\gamma$ eggs, relative to 1 for euphallics. Eggs and sperm are therefore assumed to be used in equal numbers.
Whether or not this is exactly true, the numbers involved will be much more nearly equal than when sperm are transferred to another individual. The fraction of gametes produced by hemiphallics which are used in self-fertilization is $s$. For every sperm produced by the euphallic type, present at frequency $h_{1}$, the variant (hemiphallic) type produces $(1-s) \alpha+s \gamma$. Similarly, for every egg produced by the euphallics the variant type produces $(1-s) \beta+s \gamma$. Eggs and sperm combine to form the next generation. The fitness of euphallics can then be written as:

$\frac{1}{h_{1}+h_{2}(1-s) \alpha+h_{2} \gamma}+\frac{1}{h_{1}+h_{2}(1-s) \beta+h_{2} \gamma}$

and the fitness of hemiphallics as:

$\frac{(1-s) \alpha+s \gamma}{h_{1}+h_{2}(1-s) \alpha+h_{2} \gamma}+\frac{(1-s) \beta+s \gamma}{h_{1}+h_{2}(1-s) \beta+h_{2} \gamma}$.

The system is unchanging when these fitnesses are equal. Equating the two and rearranging the equation, we find:

$\frac{h_{2}}{h_{1}}=\frac{(1-s)(\alpha+\beta)+2 s \gamma-2}{(1-s)(\alpha+\beta)(1-2 s \gamma)+2 s \gamma(1-s \gamma)-2 \alpha \beta(1-s)^{2}}$.

For polymorphism both $h_{1}$ and $h_{2}$ must be greater than zero. The conditions for this are:

$\frac{1-s \gamma}{1-s}<\frac{\alpha+\beta}{2}>\frac{\alpha \beta(1-s)}{1-2 s \gamma}-\frac{s \gamma(1-s \gamma)}{(1-s)(1-2 s \gamma)}$.

If $s=0$ these conditions become those of Charnov et $a l$. except that $\alpha$ and $\beta$ are doubled; the pattern is represented graphically in Fig. 4. Polymorphism requires fitness values such that the population lies in the shaded area. When $\alpha=0$ the variant type is female and $\beta$ must be $>2$ for polymorphism, i.e. females must produce more than twice as many eggs as hermaphrodites to compensate for absence of sperm.

If a population which was entirely selfing was compared with a cross-fertilizing hermaphrodite one it would be represented in this graph by a point on the diagonal at $45^{\circ}$. Where this line meets the other lines, $\gamma=1$. With higher values of $\gamma$ the selfing population would be fitter than the cross-fertilizing one and with lower values it would be less fit. If $s>0$, and $\alpha=0$ then the population would contain two types of individual, one of which is cross-fertilizing hermaphrodite and the other partly selfs and partly acts as a female ready to receive sperm from the hermaphrodites. The outcome depends on what is, in effect, the resultant of $\beta$ and $\gamma$, the conditions being given by the inequality above. 


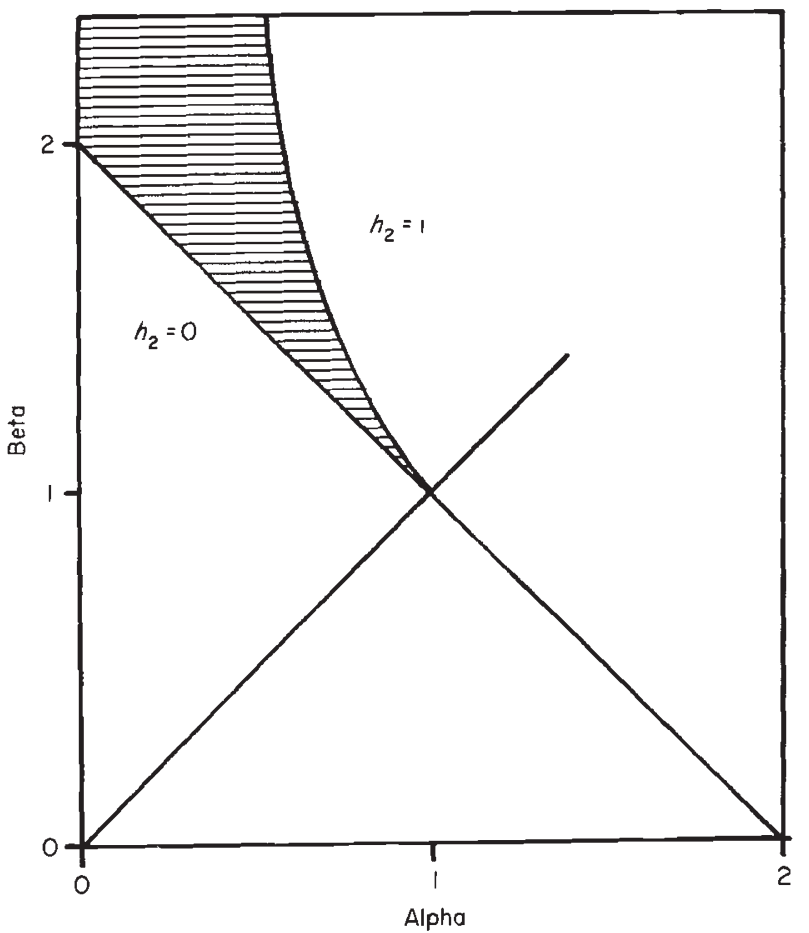

Fig. 4 Conditions for polymorphism for a variant form producing a deficiency of sperm in a hermaphrodite population where there is no selfing. Alpha = sperm produced by variant form compared with cross-fertilizing hermaphrodite; beta $=$ relative number of eggs produced. Frequency of variant form: $h_{2}$. A population is polymorphic if the values fall within the hatched area. A selfing form would have a value falling on the positive diagonal, and if the variant form was partially selfing, partially outcrossing the likelihood of polymorphism would depend on the ratio of gametes used in selfing and cross-fertilization.

A range of values will lead to polymorphism. The lower estimate of the selfing coefficient, $s$, is 0.25 . Using this value, Fig. 5 shows the values of $\beta$ and $\gamma$ for which the population will be polymorphic (solid lines). Sporadic polymorphism would arise if $\beta$ and $\gamma$ are sometimes such that populations fall between these limits. There would be no tendency for replacement of outbreeders by selfers if $\gamma$ is $<2.5$. The broken lines show the way the polymorphic region changes when $s$ is increased to 0.5 . The region becomes narrower but includes a section for which both $\beta$ and $\gamma$ are between 1 and 2 . In the snail populations examined, hemiphallics are larger than euphallics. In snails large size often leads to production of larger numbers of eggs (Baur, 1988; Peake, 1978; Wolda, 1970). A possible explanation for the variation in genitalia could therefore be that there is a polymorphism for hemiphallism, maintained because hemiphallics are female biased crossfertilizers which may also self-fertilize. These remarks

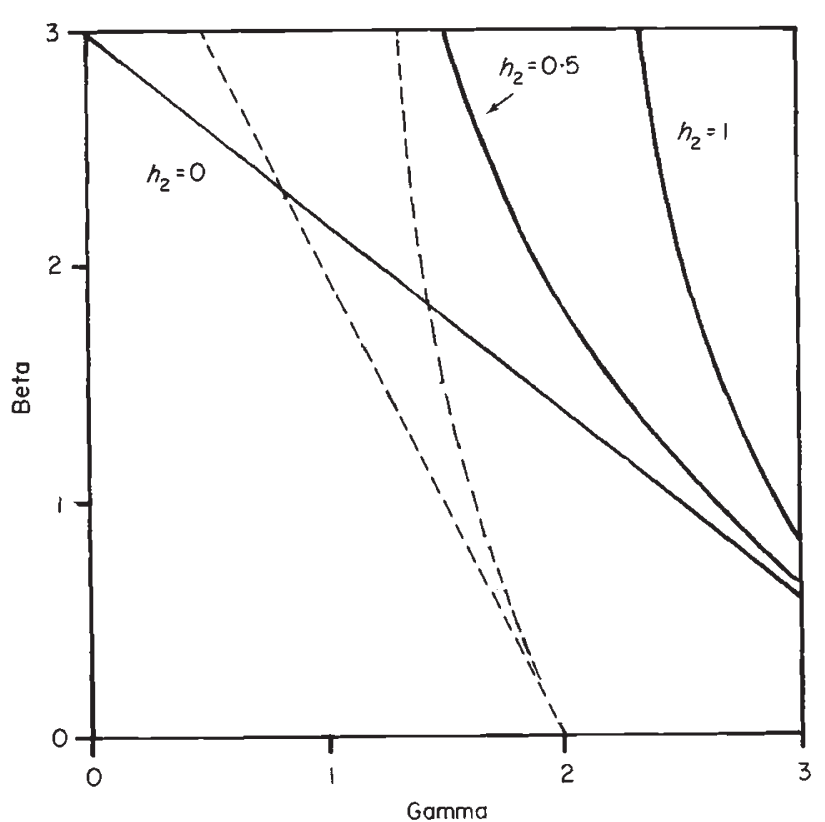

Fig. 5 Conditions for polymorphism when $\alpha=0 .(-)$ frequency of gametes used in selfing in the variant form $=0.25 ;(--)$ selfing frequency $=0.5$. Frequency of variant form: $h_{2}$.

are speculative, but they draw attention to the variety of types of sex apportionment that are possible in pulmonate snails and have been little investigated.

\section{Acknowledgements}

This work was supported by an SERC research studentship. We thank G. S. Mani and L. R. Noble for discussion.

\section{References}

BACKHUYs, w. 1975. Zoogeography and Taxonomy of the Land and Freshwater Molluscs of the Azores. Backhuys and Meesters, Amsterdam.

BAUR, B. 1988. Population regulation in the land snail Arianta arbustorum: density effects on adult size, clutch size and incidence of egg cannibalism. Oecologia, 77, 390-394.

CHARNOV, E. L., MAYNARD SMITH, J. AND BULL, J. J. 1976. Why be an hermaphrodite? Nature (Lond.), 263, 125-126.

COOK, L. M., GOODFRIEND, G. A. AND CAMERON, R. A. D. 1992. Changes in the land snail fauna of eastern Madeira during the Quaternary. Phil. Trans. R. Soc. B, 335, in press.

DAMGAARD, C., COUVET, D. AND LOESCHCKE, v. 1992. Partial selfing as an optimal mating strategy. Heredity, 69, 289-295.

FOLTZ, D. W., OCHMAN, H., JONES, J. S., EVANGELISTI, S. M. AND SELANDER, R. K. 1992. Genetic population structure and breeding systems in arionid slugs (Mollusca: Pulmonata). Biol. J. Linn. Soc., 17, 225-241. 
GERMAIN, L. 1930. Mollusques Terrestres et Fluviatiles. Lechevalier, Faune de France 21, Paris.

HARTL, D. L. AND Clark, A. G. 1989. Principles of Population Genetics. Sinauer Associates, Sunderland, MA, p. 293.

HILLIS, D. M. 1989. Genetic consequences of partial selffertilization on populations of Liguus fasciatus (Mollusca: Pulmonata: Buliminidae). Am. Malacol. Bull., 7, 7-12.

HILlIS, D. M., DIXON, M. T. AND JONES, A. L. 1991. Minimal genetic variation in a morphologically diverse species (Florida tree snail, Liguus fasciatus). J. Hered., 82, 282-286.

LACE, L. A. 1990. Variation in a Molluscan Species Complex in Madeira.Ph. D Thesis, University of Manchester.

LACE, L. A. 1992. Variation in the genitalia of the land snail Heterostoma paupercula (Lowe, 1831) (Helicidae) in Madeira. Biol. J. Linn. Soc, 46, 115-129.

Lowe, R. T. 1831. Primitiae faunae et florae Maderae et Portus-Sancti. Trans. Camb. Phil. Soc., 4, 5-66.

MANDAHL-BARTH, G. 1943. Systematische Untersuchungen über die Helicidenfauna von Madeira. Abh. Senkenberg. Naturf. Ges., 469, 1-93.

MAYNARD SMITH, J. 1978. The Evolution of Sex. Cambridge University Press, Cambridge.

PEAKE, J. F. 1978. Distribution and ecology of the Stylommatophora. In: Fretter, V. and Peake, J. F. (eds)
Pulmonates, vol. 2A, Academic Press, New York, pp. 429-526.

REIDEL, A. 1953. Male copulatory organ deficiency in the Stylommatophora with special reference to Retinella nitens (Mich). Ann. Mus. Zool. Polonici, 15, 83-100.

SELANDER, R. K. AND KAUFMAN, D. W. 1973. Self-fertilization and genetic population structure in a colonizing land snail. Proc. Nat. Acad. Sci, U.S.A., 70, 1186-1190.

TOMPA, A. s. 1984. Land snails (Stylommatophora). In: Tompa, A. S., Verdunk, N. H. and van den Biggelaar, J. A. M. (eds) The Mollusca, Reproduction, vol. 7, Academic Press, New York, pp. 47-140.

WALDÉN, H. W. 1983. Systematic and biogeographical studies of the terrestrial Gastropods of Madeira. With an annoted checklist. Ann. Zool. Fenn., 20, 255-275.

WATSON, H. 1934. Genital dimorphism in Zonitoides. J. Conchol. 20, 33-42.

WILliamson, M. H. 1959. Studies on the colour and genetics of the black slug. Proc. $R$. Phys. Soc. Edin., 27, 87-93.

WOLDA, H. 1970. Variation in growth rate in the landsnail Cepaea nemoralis. Res. Popul. Ecol., 12, 185-204.

wollaston, T. v. 1878. Testacea Atlantica or the Land and Freshwater Shells of the Azores, Madeira, Salvages, Canaries, Cape Verdes and Saint Helena. Reeve, London. 